\title{
Fatores que, na Visão da Mulher, Interferem no Diagnóstico Precoce do Câncer do Colo do Útero
}

\author{
Factors that, in the view of Women, Impede the Early Diagnosis of Cervical Cancer \\ Factores que, en la Visión de la Mujer, Interfieren en el Diagnóstico Precoz del Cáncer del Cuello del Útero
}

\author{
Maria Aparecida da Silva'; Hilda Guimarães de Freitas'²; Regiane Luz Ribeiro²; Maiene Nádia Lopes Oliveira²; Fabiana Cavalcante \\ de Araújo Sanches ${ }^{3}$; Luiz Claudio Santos Thuler ${ }^{4}$
}

\begin{abstract}
Resumo
Introduçáo: No Brasil, o câncer do colo do útero é a quarta causa de morte por câncer em mulheres. O número de casos novos estimado para 2018 é de 16.370, com um risco de 15,43 casos a cada 100 mil mulheres. Objetivo: Identificar quais são os fatores que, na visão da mulher, interferem no diagnóstico precoce do câncer do colo do útero. Método: Foi realizado um estudo descritivo quanti-qualitativo constituído de uma abordagem transversal ancorada na técnica de investigação de eventos sentinela e uma abordagem qualitativa utilizando análises de conteúdo de categorias temáticas. Foram entrevistadas mulheres com câncer do colo do útero, em estádio avançado, atendidas por serviços de saúde do Sistema Único de Saúde em Campo Grande, Mato Grosso do Sul, em janeiro e fevereiro de 2012. Resultados: Participaram da pesquisa sete mulheres com idades entre 37 e 54 anos. As entrevistadas mostraram-se desinformadas sobre a utilidade do exame preventivo, relataram que não se percebiam como alvo das ações de saúde específicas, apresentaram desespero, dor, indignação, medo, incapacidade e negação frente ao diagnóstico de câncer. Também informaram que recorreram a tratamentos alternativos, apoiaram-se em suas crenças e em familiares para superar os efeitos da doença e apontaram falhas dos serviços de saúde. Conclusáo: Estes resultados apontam para a necessidade de estudos futuros sobre o tema, focalizando nas práticas dos trabalhadores da área da saúde e no processo educativo realizado no contexto das açóes de atenção integral à saúde da mulher.
\end{abstract}

Palavras-chave: Neoplasias do Colo do Útero; Diagnóstico Precoce; Vigilância de Evento Sentinela; Análise Qualitativa.

\begin{abstract}
Introduction: In Brazil, cervical cancer is the fourth leading cause of cancer death in women. It is estimated that there will be 16,370 new cases in 2018, translating to an incidence of 15.43 cases per 100,000 women. Objective: To identify the factors that, in the view of women, impede the early diagnosis of cervical cancer. Method: This was a descriptive quantitative and qualitative study consisting of an epidemiological approach anchored in the investigation of sentinel events and a qualitative approach based on content analyses of thematic categories. We interviewed women with advanced stage cervical cancer treated in January and February of 2012 at health care facilities operated by the Unified Health System in the city of Campo Grande, in the state of Mato Grosso do Sul. Results: The study included seven women between 37 and 54 years of age. The interviewees proved to be uninformed about the usefulness of preventive screening and reported that they do not see themselves as the target of specific health interventions. When faced with the diagnosis of cancer, they showed despair, pain, anger, fear, incapacitation, and denial. They also reported having made use of alternative treatments, having relied on their beliefs and on family members to deal with the effects of the disease, and having noted shortcomings of the health care facilities. Conclusion: Our results indicate the need for future studies on the subject. Such studies should focus on health care worker practices and on the educational process carried out in the context of comprehensive health care interventions for women. Key words: Uterine Cervical Neoplasms; Early Diagnosis; Sentinel Surveillance; Qualitative Analysis.
\end{abstract}

\begin{abstract}
Resumen
Introducción: En Brasil, el cáncer de cuello de útero es la cuarta causa de muerte por cáncer en las mujeres. El número de casos nuevos estimado para 2018 es de 16.370 , con un riesgo de 15,43 casos por cada 100 mil mujeres. Objetivo: Objetivó-se identificar los factores que, en la opinión de las mujeres, interfieren en la detección precoz del cáncer del cuello del útero. Método: Se realizó un estudio cualitativo y cuantitativo descriptivo basado en la técnica de investigación de eventos centinela y análisis de contenido temático. Interrogamos mujeres con cáncer del cuello del útero en estadio avanzado, atendidas por los servicios de salud del Sistema Único de Salud en Campo Grande, Mato Grosso do Sul, en enero y febrero de 2012. Resultados: Participaron de la encuesta siete mujeres con edades entre 37 y 54 años. Las entrevistadas se mostraron desinformadas acerca de la utilidad del examen preventivo, afirmaron que no se consideravan como objetos de las acciones sanitarias específicas y mostraron desesperación, dolor, indignación, miedo, incapacidad y negación frente al diagnóstico de cáncer. También informaron que recurrieron a tratamientos alternativos, se basaron en sus creencias ya en la familia para superar los efectos de la enfermedad y seńalaron fallas de los servicios de salud. Conclusión: Estos resultados apuntan a la necesidad de estudios futuros sobre el tema, enfocándose en las prácticas de los trabajadores del área de la salud y en el proceso educativo realizado en el contexto de las acciones de atención integral a la salud de la mujer. Palabras clave: Neoplasias del Cuello Uterino; Diagnóstico Precoz; Vigilancia de Guardia; Análisis Cualitativo.
\end{abstract}

${ }^{1}$ Consultora. Campo Grande (MS), Brasil.

${ }^{2}$ Secretaria de Estado de Saúde do Mato Grosso do Sul (SES/MS). Campo Grande (MS), Brasil.

${ }^{3}$ Secretaria Municipal de Saúde Pública de Campo Grande (Sesau). Campo Grande (MS), Brasil.

${ }^{4}$ Instituto Nacional de Câncer José Alencar Gomes da Silva (INCA). Universidade Federal do Estado do Rio de Janeiro (Unirio). Rio de Janeiro (RJ), Brasil. Endereço para Correspondência: Hilda Guimarães de Freitas. Gerente Estadual da Saúde da Mulher/Atenção Básica. Parque dos Poderes: Bloco 7 - Campo Grande (MS), Brasil. CEP 79031-902.E-mails: sdmulher@saude.ms.gov.br e hildagfreitas@gmail.com. 


\section{INTRODUÇÃO}

No Brasil, o câncer do colo do útero é a quarta causa de morte por câncer em mulheres. O número de casos novos estimado para 2018 é de 16.370, com um risco de 15,43 casos a cada 100 mil mulheres ${ }^{1}$. Em Mato Grosso do Sul, a estimativa é de 20,49 casos novos/100 mil mulheres ${ }^{1}$. Em relação à mortalidade, entre 2006 e 2015, o Estado apresentou taxas de mortalidade ajustadas por idade entre 4,58 e 8,55 por 100 mil mulheres, sendo a faixa etária mais atingida a que contempla as mulheres de 50 a 59 anos (22,8\% dos casos), seguida por aquelas entre 40 e 49 anos $(20,3 \%)$ e as entre 60 e 69 anos $(19,1 \%)^{2}$.

A Organização Mundial da Saúde estima que aproximadamente $80 \%$ da mortalidade por câncer do colo do útero pode ser reduzida pelo rastreamento na faixa de 25 a 60 anos, por meio do teste de Papanicolaou e tratamento adequado das lesóes precursoras com alto potencial de malignidade ou carcinoma in situ. A eficiência desses procedimentos depende da organização da rede de serviços, da integralidade da atenção, da qualidade do programa de rastreamento e seguimento das pacientes com alteraçôes no exame citopatológico e, sobretudo, da participação consciente das mulheres nesse processo.

Cabe destacar que os fatores que levam as mulheres a não se submeterem ao exame de Papanicolaou têm sido reincidentes em diferentes estudos nacionais e comumente estão ligados a: baixo nível socioeconômico, baixa escolaridade, baixa renda familiar e ao fato de as mulheres pertencerem a faixas etárias mais jovens ${ }^{4}$. Entretanto, ao discorrer sobre o desafio de reduzir a mortalidade por câncer do colo do útero, Zeferino ${ }^{5}$ acrescenta aos fatores relacionados à mulher aqueles relacionados aos serviços de saúde. Segundo esse autor, neste último grupo, destacam-se aqueles sobre os quais seriam possíveis ações em curto prazo: 1) qualidade para garantir diagnóstico correto e realizar tratamento preciso; 2) acesso fácil e ágil aos serviços; 3) flexibilidade para marcar e remarcar consultas; e 4) rapidez no atendimento. Destaca ainda que, além de garantir a cobertura de $70 \%$ a $80 \%$ do exame de Papanicolaou - o que já é realidade em muitas localidades do país -, é importante que as mulheres que tenham um exame alterado recebam tratamento adequado. Por sua vez, Thuler ${ }^{6}$ destaca que o diagnóstico do câncer do colo do útero em estádio avançado reflete problemas no acesso aos serviços, agravado, sobretudo, pela carência de centros de oncologia fora das grandes capitais do país. Já Osawa e Marcopito ${ }^{7}$ defendem que os problemas de acesso não se esgotam nas características socioeconômicas dos indivíduos, mas associam-se à oferta e à organização dos serviços de saúde. Além desses fatores, há que se destacar ainda o encaminhamento equivocado para serviços secundários de pacientes com colpocitologia compatível com células atípicas de significado indeterminado (reativa) ou de lesão intraepitelial de baixo grau - que deveriam repetir o exame em seis meses - provocando sobrecarga dos serviços, em desacordo com as normas do Ministério da Saúde ${ }^{8,9}$.

Diante desse contexto, optou-se pela realização desta pesquisa com o propósito de identificar quais sáo os fatores que, na visão da mulher, interferem no diagnóstico precoce do câncer do colo do útero.

\section{MÉTODO}

Foi realizado um estudo descritivo quanti-qualitativo constituído de uma abordagem transversal ancorada na técnica de investigação de eventos sentinela e uma abordagem qualitativa utilizando análises de conteúdo de categorias temáticas. A partir do olhar das mulheres entrevistadas, objetivou-se avaliar as práticas de saúde, detectar as falhas nas formas de organização dos serviços e na relação com as usuárias sujeitas desta pesquisa. Foi ainda elaborado o modelo lógico do Programa de Prevenção do Câncer do Colo do Útero desenvolvido no Estado, conforme roteiro básico proposto pelo Instituto de Pesquisa Econômica Aplicada (Ipea) ${ }^{10}$, contendo os seguintes elementos: recursos, operaçóes/ açôes, produtos, resultados intermediários e finais (Figura 1). Além disso, utilizou-se uma análise de conteúdo de categorias temáticas, com vistas a estudar as representaçôes sociais e identificar os conhecimentos, informaçôes e compreensão dos sentimentos e significados que a doença pode ter, e a forma como a mulher a enfrenta. Para isso, foram construídas operaçôes de desmembramento do texto em unidades de significado, segundo as categorias preestabelecidas, consistindo em identificar núcleos de sentido, descrevendo-os e quantificando-os quanto aos seus significados.

O estudo foi realizado na Secretaria de Estado de Saúde de Mato Grosso do Sul. O Estado apresentava em 2010 Índice de Desenvolvimento Humano Municipal (IDHM) de 0,729 , segundo melhor na Região e décimo no ranking nacional ${ }^{11}$. Segundo o Instituto Brasileiro de Geografia e Estatística (IBGE) ${ }^{12}$, dos 2.449 .024 habitantes residentes no Estado em 2010, 1.229.096 eram do sexo feminino $(50,2 \%)$. A expectativa média de vida das mulheres era a nona maior no contexto nacional, 77,7 anos.

Em decorrência do delineamento do estudo, optou-se por analisar uma amostra intencional na qual a inclusão de mulheres foi finalizada pelo critério de saturação; ou seja, quando os discursos passaram a apresentar elementos em comum, pouco acrescentando às informações já colhidas. Foram incluídas neste estudo mulheres na faixa etária 
Objetivo geral do Programa: Diminuir a incidência e a mortalidade por câncer do colo do útero

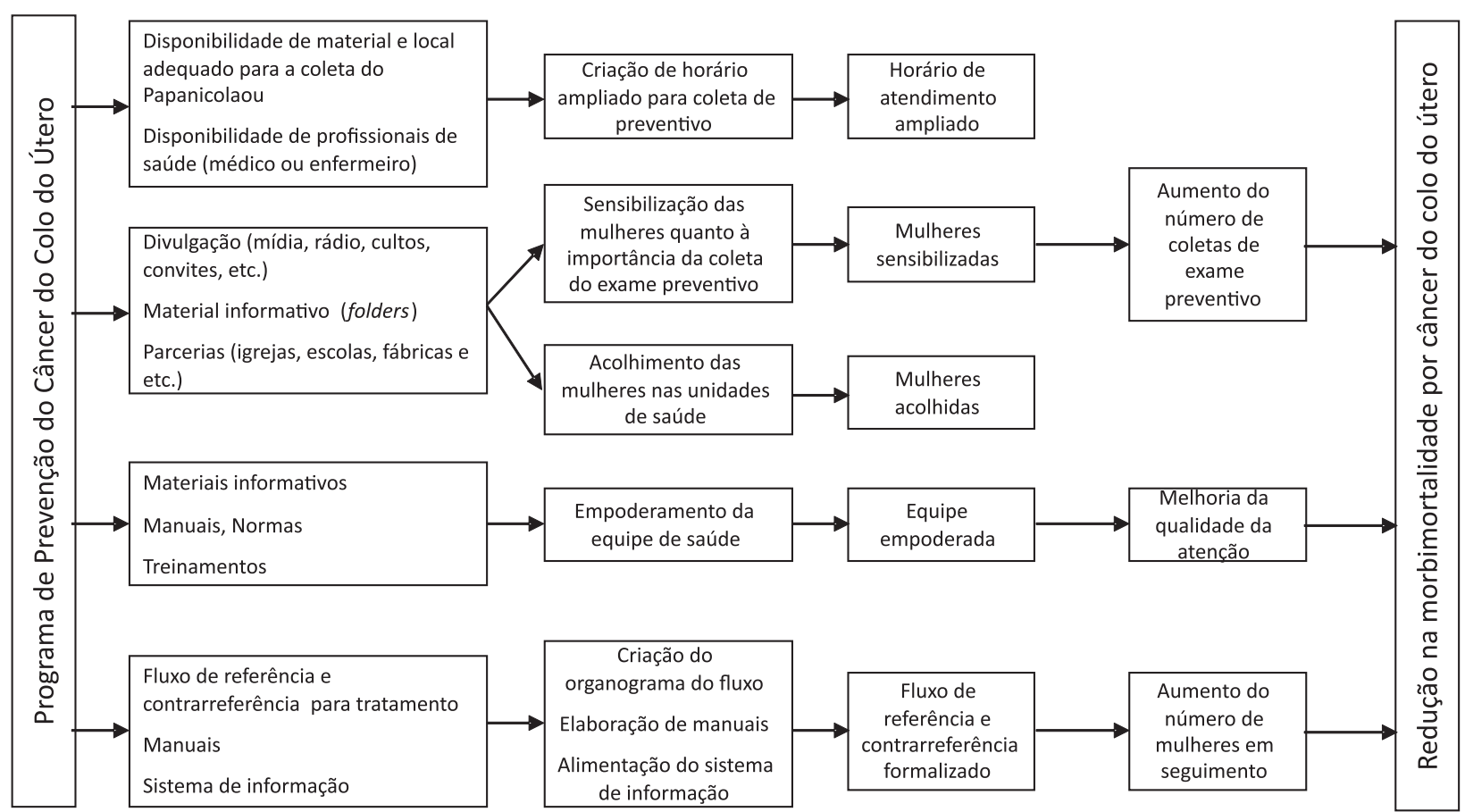

Figura 1. Modelo Lógico do Programa de Prevenção do Câncer do Colo do Útero

entre 25 e 59 anos, atendidas por serviços de saúde do Sistema Único de Saúde (SUS), em janeiro e fevereiro de 2012, residentes no Estado de Mato Grosso do Sul, com história de câncer do colo do útero em estádio avançado, que concordaram em participar da pesquisa, assinando o Termo de Consentimento Livre e Esclarecido (TCLE). A entrevista foi a única fonte de dados, sendo composta por questóes norteadoras, fechadas e abertas. Os dados foram coletados por entrevistador treinado e habilitado para esse fim. O projeto foi aprovado pelo Comitê de Ética em Pesquisa (CEP) da Universidade Federal de Mato Grosso do Sul (UFMS), em 19 de outubro de 2011, sob o número de protocolo ${ }^{\circ}$ 2195 CAAE 0289.0.0.049.000-11.

\section{RESULTADOS E DISCUSSÃO}

\section{PeRFIL SOCIODEMOGRÁFICO}

Foram entrevistadas sete mulheres com idade entre 37 e 54 anos, em sua maioria solteiras $(57,1 \%)$, brancas (85,7\%), com inserção no mercado de trabalho doméstico $(85,7 \%)$ e que recebiam entre um e três salários mínimos por mês $(71,4 \%)$. Quanto à educação formal, 71,4\% contavam com ensino fundamental incompleto e 14,3\%, com superior completo. É importante ressaltar que o nível educacional é primordial para a adesão às açôes de prevenção à saúde, notadamente às ações de detecção precoce do câncer do colo do útero. Vários estudos demonstraram que mulheres com maior acesso à educação formal cuidam melhor de sua própria saúde e da saúde de seus familiares e procuram com mais frequência os serviços de saúde ${ }^{4}$. Pode-se observar ainda que 42,9\% das mulheres estavam há mais de três anos sem realizar o exame de Papanicolaou. Em estudo realizado em Roraima, Fonseca et al. ${ }^{13}$ identificaram, de forma semelhante, que $71,7 \%$ das mulheres com câncer do colo do útero ou lesões pré-malignas de alto grau nunca haviam realizado o teste de Papanicolaou.

\section{PASSOS E DESCOMPASSOS ENTRE O SABER TÉCNICO E O SABER POPULAR}

Cada mulher, sujeito da pesquisa, tem informaçóes e ideias particulares a respeito do conceito do exame citológico do colo do útero e de suas especificidades. Entre as respostas, $100 \%$ delas náo souberam responder para que serve o exame preventivo, embora $85,7 \%$ tenham informado que receberam os resultados do exame como destacado nas falas a seguir:

Eu não sei, só sabia que minha mãe falava que tinha que fazer todo ano. Eu fiz quando eu tinha 
escorrimento (diarista, 44 anos); Serve prá saber tudo né, prá saber se tem alguma doença. Para prevenir muita coisa (mulher do lar, 43 anos); Para os problemas de vagina, do útero (cozinheira, 40 anos); Prá ver se tem bactéria, para descobrir a doença no início (cozinheira, 54 anos); Eu nunca vi falar (cozinheira de fazenda, 46 anos).

Cabe destacar que, em outro estudo, o desconhecimento também foi o motivo mais relatado pelas mulheres para não realizarem o exame preventivo, perfazendo $47,4 \%$ dos $\operatorname{casos}^{13}$.

\section{INFORMAÇÕES SOBRE 0 PREVENTIVO DO CÂNCER DO COLO DO ÚTERO}

Nas transcriçôes a seguir, pode ser identificado o quanto as mulheres estáo informadas sobre o preventivo do câncer do colo do útero e onde receberam essas informaçôes:

Sim, tinha alguma informaçáo geral, muito vaga. Eu sabia que ela estava lá. Elas não vinham ao meu encontro e eu não ia ao encontro delas. Não me sensibilizou. Não era uma publicidade em cima do assunto. Cartaz náo motiva a gente ler. Eu sabia que tinha que fazer exames, mas sentia que esse assunto não fazia parte da minha vida. Via as pessoas falar que fulana morreu de câncer, que fulana tava com câncer, mas... (professora universitária, 37 anos).

Esse depoimento é revelador do desencontro entre as percepções, saberes, atitudes e práticas educativas centrados em normas técnicas e que não motivam, não oferecem subsídios e nem autonomia ao sujeito para agir diante dos seus problemas de saúde, especialmente na busca da prevenção do câncer, seja do colo do útero, de mama e de outras localizaçóes. Essa percepção da usuária em relação aos serviços revela ainda a negação da doença. O problema existe para os outros, como pode ser observado nas falas a seguir:

Sabia em conversa com enfermeiro. Eu não era de ir a médico, só pra levar as crianças quando tava com dor de ouvido, coisa assim. Quando eu machuquei, eu fiz consulta (cozinheira, 40 anos); Eu não tinha informação, não sabia como pega essa doença. Até agora não sei. Eu pergunto para os médicos, eles só falam que tenho que tratar (diarista, 44 anos); $\mathrm{Eu}$ via as mulher falar desse câncer, mas da onde eu ia pensar? Eu nunca vi falar sobre prevenção. Papanicolaou também não (mulher do lar, 43 anos).

Essas percepções demonstram que a relação entre trabalhadores e usuários e a educação em saúde devem ser estratégias capazes de revelar poder, sensibilizar, motivar e dar subsídios às mulheres para desenvolverem suas potencialidades no campo do conhecer, assim como aprofundar o conhecimento sobre sua saúde, sua realidade de vida, sobre as relaçóes sociais estabelecidas entre o poder público e entre si, além de dar suporte à mudança de atitude, de valores e costumes, como também às escolhas para viver em sociedade, participando nos assuntos públicos. Desse ponto, vale recorrer a Freire, Gadotti e Guimarães ${ }^{14}$ que defendem que, em se tratando da democratização do saber, duas questôes devem ser levadas em conta: a primeira diz respeito ao cidadão ter direito de conhecer melhor o que ele já conhece, a partir de sua prática. Ninguém pode negar que cada sujeito tem um saber e que os trabalhadores da saúde, os educadores e outros atores sociais podem apoiá-lo para conhecer melhor esse seu saber. A segunda refere-se ao fato de o cidadão ter o direito de conhecer o que ele ainda não conhece, ou seja, ele possui o direito de participar da produção de novos conhecimentos, começando por responder às seguintes questóes: produzir o que, para quem, contra quem e contra o que.

Outro aspecto que merece destaque nas falas das mulheres é que, apesar de alertadas para a necessidade de seguimento após a detecção de lesôes precursoras, algumas não aderem às recomendaçôes recebidas, como exposto a seguir:

Eu fiz o exame há mais ou menos seis anos atrás. Minha mãe dizia que tinha que fazer todo ano. $\mathrm{O}$ médico falou que tinha uma feridinha, aí fiz um pouco de tratamento. Daí parei... Fui viver minha vida, eu não tinha ninguém por mim, tinha que dar conta dos meus filhos. Daí não fiz mais preventivo (diarista, 44 anos); Há três anos atrás, minha médica fez o Papanicolaou e deu uma inflamação, isso durante a gravidez da minha terceira filha. Eu não tinha nada. Era saudável. Sabia que tinha uma inflamação e que deveria retornar após o parto, mas não retornei (professora universitária, 37 anos).

Já na fala a seguir, a entrevistada apresenta sua ideia de como os serviços de saúde deveriam pautar as açôes educativas ou de mobilização social:

Talvez seja necessário realizar campanha mais direcionada, fazer maior pressáo psicológica, campanha que chame a atenção, forte, que aponte a responsabilidade das pessoas com elas próprias. A gente pensa que nunca vai acontecer com a gente... Prevençáo, eu sabia que tinha que ser feita, ninguém dava ênfase. A gente, principalmente quem tem família, filho, não liga muito (professora universitária, 37 anos). 
Além dos profissionais de saúde como fontes de informação, nas falas seguintes, a Internet foi apontada como importante recurso para as pacientes se manterem informadas:

Eu busquei na Internet e sabia tudo. Vi que era muito grave, sabe? (cozinheira, 40 anos); Sim, fiquei com muitas dúvidas, muitas. Procurei na Internet. Não sei se é bom saber, você se apavora. É bom não saber nada (mulher do lar, 43 anos)

\section{REAÇÕES, ATITUDES E SENTIMENTOS: DESESPERO DIANTE DO DIAGNÓSTICO DO CÂNCER DO COLO DO ÚTERO}

Podem-se verificar, a seguir, os depoimentos de como as mulheres se sentiam ao saber o resultado do exame citológico do colo do útero. Em geral, expressam desespero, dor, indignaçáo, medo, incapacidade e, muitas vezes, negação da doença. Além disso, o câncer é uma doença que traz consigo um forte estigma, a ponto de ter seu nome omitido ou impronunciável muitas vezes. Há ainda a compreensão de que câncer é sinônimo de morte prematura e sofrimento do doente, como relatado a seguir:

Pensei na morte. Câncer é morte. Foi muito sofrido. Eu pesava que era o aniquilamento da pessoa. Um dia um amigo me encontrou e me disse: mas você está bem! Sim, essa doença tem cura, bem. Agora eu sei, ela pode ser controlada. Eu resisti, resisti muito, ser atendida pelo hospital do câncer. Eu achava terrível falar dessa doença. Fiz de tudo, procurei médico particular. Meu médico me segurou até onde deu (professora universitária, 37 anos); Só falei pra minha filha, chorava e falava que nem adiantava fazer tratamento. A única coisa que sabia é que essa doença não tinha cura. Eu fiquei muito mal, achei que não tinha mais cura, que era o fim da vida (cozinheira, 54 anos); Muito mal. É difícil. Eu ainda não acredito que estou doente. Realmente eu não sinto que tô com essa doença, câncer maligno no útero. $\mathrm{O}$ momento mais difícil é saber que você tá com essa doença: câncer maligno no útero (diarista, 44 anos).

Todas as entrevistadas afirmaram que receberam o resultado positivo do exame dos seus médicos. $\mathrm{O}$ comportamento, as emoçóes, os sentimentos, expressos nesse momento, respondem alguns dos principais propósitos desta pesquisa, em relação a ter acesso aos sentimentos, reaçôes, atitudes e ao significado do câncer para as mulheres, face ao diagnóstico de câncer do colo do útero. Conforme destaca Moscovici ${ }^{15}$, em todas as culturas conhecidas, existem normas que conduzem à individualização e outras que levam à socialização. A partir desse olhar, pode-se então dizer que as representações que essas culturas elaboram carregam os traços, as raízes da ambiguidade, conferindo-lhes sentido em relação ao processo saúde-doença, morte e vida.

Outro aspecto importante desta pesquisa diz respeito ao foco sobre a sexualidade e às questôes de gênero, o que pode ser apreendido a partir da fala seguinte:

Eu não senti, mas não senti nada. Pro meu marido eu era uma "mala sem alça", sabe? Falei pra ele: vamos separar logo. Se fosse você, pensa: esperar seis anos pra curar. Ele não quer separar. Já fazia um ano que quase não tinha relação sexual. Eu tinha muita dor. Ele bebe muito. Mas quando está sem beber é uma pessoa boa... Eu penso em largar dele. Eu já não posso ser mulher dele, sabe né? $\mathrm{O}$ mais difícil é no momento de saber do diagnóstico. As pessoas te olham diferente, as pessoas abandonam a gente. Penso que é por medo de você pedir ajuda ou alguma coisa pra elas (cozinheira, 41 anos).

Para entender esse comportamento citado, é importante lembrar que o tema câncer do colo do útero, câncer de mama, prazer e vida sexual estão diretamente ligados à sexualidade, às questôes de gênero e compóem os elementos do corpo da mulher, corpo este que representa o "templo da proibição". Portanto, falar dessas questôes não é nada fácil, e pode acarretar alguns constrangimentos.

\section{ESTRATÉGIAS DE CURA: TRATAMENTOS ALTERNATIVOS}

Quando questionadas sobre o uso de tratamentos alternativos ou uso de fitoterápicos, as mulheres revelaram suas buscas, conforme descrito a seguir:

Usei várias coisas: chá de ipê-roxo, algas, clorela. A clorela é muito usada. Ela é usada até pelos astronautas como complemento. Ela é uma alga poderosíssima, um naturalista estudioso quem indicou. Usei cápsulas de graviola por dois meses. Depois voltou tudo (professora universitária, 37 anos); Tomei chás de ipê-roxo, rosa-branca, carrapichinho e outros. Usei antes e depois do tratamento médico. Quando comecei a rádio, eu parei. O mais difícil agora é comprar os medicamentos. Sáo caros. Eu quero falar com a Assistente Social, preciso de ajuda. O meu caso é muito avançado, tenho que tomar tarja preta. É!... (cozinheira, 40 anos); Quando eu tava com mioma sim, chá de casca de piúva, punha também no chimarrão, fedegoso, para tudo, barbatimão. Tudo que o pessoal falava prá eu tomar, eu tomava pra acabar a dor. Mas quando apertou mesmo a dor, eu vim pra Corumbá (cozinheira de fazenda, 46 anos); Sim, chá caseiro: arnica com sangra d'água. Minha mãe fez o chá (mulher do lar, 43 anos).

Diante dessas escolhas dos medicamentos alternativos e chás e da crença no poder deles no alívio da dor e na 
cura da doença, pode-se dizer que, em geral, a forma sob a qual se apresentam os diversos medicamentos, sejam eles químicos ou naturais, não é independente da ideia que a população tem da sua natureza e da sua eficácia. Alguns autores, entre eles Loyola ${ }^{16}$, Boltanski ${ }^{17}$ e Helman ${ }^{18}$, dizem que os medicamentos são ordenados e hierarquizados pela populaçáo em valores que vão desde o menos eficaz ao mais eficaz, do menos perigoso ao mais perigoso, do mais fraco ao mais forte, dos bons aos ruins.

\section{ESPERANÇA DE CURA E RELAÇ̃̃ES INTERPESSOAIS}

As falas das mulheres no que diz respeito às expectativas de cura, crenças, religiosidade e relaçôes interpessoais são expressas nas falas seguintes:

Agora tô melhor, graças a Deus (risos). Eu não era nada, mas fui na Evangélica. Ontem eu recebi pelo correio essa santinha: Nossa Senhora da Graça. Eu estou usando e dei doação pra eles. Dizem que essa santa é milagrosa. Bem, é bom ajudar as pessoas (cozinheira, 40 anos); Eu tive que procurar uma religiāo para me dar suporte. Meu psicológico estava muito abalado, eu senti falta. Em casa não tem religião, meu marido não tem. Foi a Messiânica que me encontrou aqui no hospital. $\mathrm{Eu}$ vi as pessoas recebendo o Jorei e quis receber. É muito bom (professora universitária, 37 anos); Eu fui pra cirurgia 7 h40 da manhã e saí 1 hora da tarde. Fui fazer o mioma. Eu não sabia, nem o médico sabia. Quando o médico abriu, que ele viu tudo, né! Daí como já tinha operado tudo, eu fiquei querendo saber se era verdade. Minha mãe falava pra mim: tomara que não seja, minha filha. Reza, que você tem fé e vai sarar. Agora eu tô feliz. Com fé em Jesus Cristo, tô curada (cozinheira de fazenda, 46 anos); Entrego tudo nas mãos de Deus (diarista, 44 anos).

Com essas referências, foi possível compreender o ponto de vista e os sentimentos das mulheres.

\section{APOIO DA FAMÍLIA}

Outro aspecto que mereceu destaque nesta pesquisa foi a relação das mulheres com suas famílias nesse momento de fragilidade. Embora alguns estudos apontem a família como cuidadora e essencial para as pessoas com câncer e demais doenças graves, nem todas as mulheres entrevistadas tiveram as mesmas percepçóes. Algumas apontaram as reaçóes dos familiares ao diagnóstico do câncer como um elemento a mais a ser enfrentado, pois, apesar do desespero diante da própria doença, ainda tiveram que ampará-los, conforme indicado nas falas a seguir:
Eu mesma que me dei o maior apoio. Eu um dia falei: vou levantar. Eu fiquei nove dias deitada, perdi sete quilos. Falei: de hoje ninguém mais vai falar o que eu tenho que fazer. Pai e mãe só falam que não é nada. Pessoas que eu pensava que iria tá do meu lado, não tava, as que eu náo esperava, tava... Meu marido me dá apoio. Ele fala com o patrão dele quando precisa alguma coisa (cozinheira, 41 anos); Contei para meu esposo, depois para a família. Eu tive que superar, digerir, pois eles ficaram muito abalados. Mais que eu. Minha família fala que isso não é nada dessa doença. Eles não creem ou falam pra mim ficar calma (professora universitária, 37 anos); Minha família falava: Ah! Isso não é nada não (cozinheira, 40 anos).

O apoio da família também foi destacado por Panobianco et al. ${ }^{19}$ como importante estratégia de enfrentamento do câncer do colo do útero, ao lado da fé e da realização de atividades prazerosas como dançar, passear e conversar com familiares. Todavia, não se pode negar o seu caráter contraditório, cuja dinâmica cotidiana de convivência é marcada por conflitos e, geralmente, por desigualdades sociais, além de, nas sociedades capitalistas, assegurar a proteção social dos seus membros ${ }^{20}$.

\section{DEMANDA POR SERVIÇOS DE SAÚDE: UMA DIFÍCIL TRAVESSIA}

Seguindo a técnica recomendada para estudos de eventos sentinela, pode-se reconstruir a história dessas mulheres e dos atendimentos recebidos, identificando possíveis falhas existentes. Nota-se que, em alguns casos, as mulheres fizeram uma verdadeira peregrinaçáo de unidade em unidade de saúde sem, contudo, terem suas necessidades atendidas, como se observa nas falas a seguir:

Há quatro anos e meio fiz exame preventivo. Dois anos atrás comecei a sentir a barriga inchada e muita dor no pé da barriga. Fiz exame e o resultado foi normal. Eu continuava a sentir muita dor no pé da barriga. Dor de bebê mesmo, sabe né? No período menstrual muita hemorragia. Aí, em fevereiro de 2011, o médico deu o diagnóstico de tireoide. Ele falou que era problema de hormônio. Toda semana eu tava no posto pra fazer tratamento da tireoide e tomar injeçôes de dor. Eu tinha muita dor. Em setembro de 2011, eu já não aguentava mais de tanta dor. Barriga inchada. $\mathrm{O}$ médico disse que não poderia por a mão em mim. Ele não era ginecologista. Mas mandou falar com a Assistente Social pra dar o encaminhamento pra fazer um ultrassom, que não deu nada. Daí mandaram fazer biópsia. Então fui. Eu tava em casa, quando eu vi o pessoal do posto chegar. Logo fiquei desconfiada. Eu ia no posto, fazia tratamento e tudo. Eles disseram que a doutora 
queria falar comigo. Eu tinha feito exame do câncer, aí eu pensei logo: vocês vieram aqui... eu tô com câncer? Fui falar com a médica. Cheguei lá, ela ficava mudando de assunto. Parece que queria passar a máo na minha cabeça, me acalmar. Eu disse: estou com 40 anos... essa dor... tô vendo tudo isso... eu tô com câncer. Daí, a médica deu o resultado. Fiquei muito nervosa e desesperada. A médica me deu diazepam pra acalmar e dormir. Olha! Muito tempo perdido, desde fevereiro até novembro. Eu mirei no médico... aquele do diagnóstico da tireoide... Foi o médico que não me ouviu. Não acreditou no que eu sentia. Olhar em mim e falar que eu tava com tireoide! Passar mais de nove meses assim. Na realidade nove meses de atraso... Que os profissionais de saúde, o médico vejam a dor da pessoa. Olhar a dor dela, seja um calo ou a unha. Não sentir a dor, mas olhar! Se eles tivessem me ouvido, não tinha ficado assim (cozinheira, 41 anos).

Notam-se claramente, nessa fala, as falhas dos serviços de saúde e o apelo da entrevistada para que os profissionais de saúde lhe dessem mais atenção, acolhimento, reconhecessem seus diretos de sujeito da ação de saúde. Cabe aqui recorrer a Berlinguer ${ }^{21}$ que afirma que alguns sinais, que fazem supor até uma doença grave, como sangramento nas fezes e na urina, ou nódulos provavelmente tumorais na mama e no abdômen, não são reconhecidos, com frequência, como suficientemente graves para suscitar atenção e cuidado dos trabalhadores de saúde. Outro aspecto que merece destaque nessa fala é a dor relatada pela paciente. Conforme destacam Silber et al. $^{22}$, a dor é um sintoma ou signo dentro do quadro de saúde mais complexo. $\mathrm{O}$ autor descreve duas categorias para distinguir a dor: dor orgânica (sinal, alerta da iminência de um processo patológico) e dor funcional (sofrimento, grito de socorro, busca de ajuda). Os autores destacam ainda que cabe ao profissional de saúde saber e poder distinguir o componente orgânico do funcional e, a ambos, deve-se destinar a mesma atenção, evitando a tentação de desqualificar o sofrimento.

\section{CONCLUSÃO}

Com as experiências dessas mulheres aqui descritas, fica evidente que a representação social deve ser compreendida e analisada a partir da sua gênese e tendo como pano de fundo as condiçôes sociais que a produzem. A realidade social tem significados específicos e uma estrutura de grande relevância para as pessoas que vivem, pensam, agem e interagem. Não se pode negar que a percepção dessas mulheres sobre a prevenção e os sintomas da própria doença estão vinculados às relaçóes com os serviços de saúde, com a família, com os amigos e são influenciados pela cultura, pelo trabalho e pela vulnerabilidade diante da exclusão social. Por fim, os resultados apontam para a necessidade de estudos futuros sobre o tema, abrangendo outras localidades, focalizando nas práticas dos trabalhadores da área da saúde e no processo educativo realizado no contexto das ações de atenção integral à saúde da mulher.

\section{AGRADECIMENTOS}

Sinceros agradecimentos às usuárias dos serviços oncológicos que, mesmo diante dos seus sofrimentos, se dispuseram a dar suas importantes contribuiçóes; e ao Hospital do Câncer Prof. Dr. Alfredo Abrão, pelo valioso apoio.

\section{CONTRIBUIÇÕES}

Maria Aparecida da Silva e Hilda Guimarães de Freitas participaram da análise, coleta e interpretação dos dados; redação do artigo; aprovação da versão a ser publicada. Regiane Luz Ribeiro; Maiene Nádia Lopes Oliveira e Fabiana Cavalcante de Araújo Sanches participaram da coleta e interpretação dos dados; revisão crítica do artigo; aprovação da versão a ser publicada. Luiz Claudio Santos Thuler participou da concepção e do delineamento do projeto; interpretação dos dados; revisão crítica do artigo; aprovação da versão a ser publicada.

\section{DECLARAÇÃO DE CONFLITO DE INTERESSES}

Nada a Declarar.

\section{REFERÊNCIAS}

1. Instituto Nacional de Câncer José Alencar Gomes da Silva. Estimativa 2018: Incidência de câncer no Brasil. Rio de Janeiro: INCA; 2017.

2. Brasil. Ministério da Saúde. Datasus. Informaçóes de Saúde. Mortalidade [internet]. Mato Grosso do Sul: Ministério da Saúde; 2018[acesso em 2018 jul 7]. Disponível em: <http://www.datasus.gov.br>.

3. World Health Organization. The World Health Organization's Fight Against Cancer: Strategies That Prevent, Cure and Care [internet]. 2007[acesso em 2018 jul 8]. Disponível em: <http://www.who. int/cancer/publicat/WHOCancerBrochure2007. FINALweb.pdf>.

4. Martins LFL, Thuler LCS, Valente JG. Cobertura do exame de Papanicolaou no Brasil e seus fatores determinantes: uma revisão sistemática da literatura. Ver. Bras. Ginecol. Obstet. [internet]. 2005 [acesso em 2018 jul 8];27(8):485-92. Disponível em: <http://www.scielo. br/pdf/rbgo/v27n8/26760.pdf >. 
5. Zeferino LC. O desafio de reduzir a mortalidade por câncer do colo do útero. Rev. Bras. Ginecol. Obstet. [internet]. 2008[acesso em 2018 jul 8];30(5): 213-215. Disponível em: http://www.scielo.br/pdf/rbgo/v30n5/ a01v30n5.pdf>.

6. Thuler LCS. Mortalidade por câncer do colo do útero no Brasil. Rev. Bras. Ginecol. Obstet. [internet]. 2008[acesso em 2018 jul 8];30(5):216-218. Disponível em: http://www.scielo.br/scielo.php?pid=S010072032008000500002\&script=sci_arttext.

7. Ozawa C, Marcopito LF. Teste de Papanicolaou: cobertura em dois inquéritos domiciliários realizados no município de São Paulo em 1987 e em 2001-2002. Rev. Bras. Ginecol. Obstet. [internet]. 2011 [acesso em 2018 jul 8];33(5):238-245. Disponível em: <http://www. scielo.br/pdf/rbgo/v33n5/a06v33n5.pdf>.

8. Albuquerque ZBP, Manrique EJC, Tavares SBN, Souza ACS, Guimarães JV, Amaral RG. Mulheres com atipias, lesôes precursoras e invasivas do colo do útero: condutas segundo as recomendaçóes do Ministério da Saúde. Rev. Bras. Ginecol. Obstet. [internet]. 2012[acesso em 2018 jul 8]; 34(6):248-253. Disponível em: <http://www. scielo.br/pdf/rbgo/v34n6/v34n6a02.pdf>.

9. Andrade JM. Limitaçóes para o sucesso do rastreamento do câncer de colo no Brasil. Rev. Bras. Ginecol. Obstet. [internet]. 2012 [acesso em 2018 jul 8];34(6):245-247. Disponível em: <http://www.scielo.br/pdf/rbgo/v34n6/ v34n6a01.pdf>.

10. Ferreira H, Cassiolato M, Gonzalez R. Nota Técnica: Como Elaborar Modelo Lógico de Programa: um roteiro básico [internet]. Brasília: IPEA; 2007[acesso em 2018 jul 8]. Disponível em: http://www.ipea.gov.br/portal/ images/stories/PDFs/2007_nt02_fevereiro_disoc.pdf.

11. Programa das Naçóes Unidas para o Desenvolvimento. Atlas do Desenvolvimento Humano no Brasil. [acesso em 2018 jul 8]. Disponível em: <htttp://www.atlasbrasil.org.br/2013/ pt/home/ >.

12. Instituto Brasileiro de Geografia e Estatística. Censo 2010. Brasília: IBGE; 2010. [internet]. [acesso em 2018 jul 8]. Disponível em: <www.ibge.gov.br/>.

13. Fonseca AJ, Ferreira LP, Dalla-Benetta A, Roldan CN, Ferreira MLS. Epidemiologia e impacto econômico do câncer de colo de útero no Estado de Roraima: a perspectiva do SUS. Rev. Bras. Ginecol. Obstet. [internet]. 2010; [acesso em 2018 jul 8]; 32(8):386-392. Disponível em: <http://www.scielo.br/pdf/rbgo/v32n8/ a05v32n8.pdf>.

14. Freire P, Gadotti M, Guimarães S. Educar e reinventar o poder [internet]. In: Freire P, Gadotti M, Guimarães S, organizadores. Pedagogia: Diálogo e Conflito. 4. ed. São Paulo: Cortez; 1995. [acesso em 2018 jul 8]. Disponível em: <http://pt.scribd.com/doc/4994255/pedagogiadialogo-e-conflito $>$.
15. Moscovici S. Representaçóes Sociais: Investigações em psicologia social. 6. ed. Petrópolis: Vozes; 2009.

16. Loyola MA. Médicos e Curandeiros. São Paulo: Difel; 1984.

17. Boltanski L. As Classes Sociais e o Corpo. 3. ed. Rio de Janeiro: Ediçóes Graal; 1989.

18. Helman CG. Cultura, Saúde e Doença. 2. ed. Porto Alegre: Artes Médicas; 1994.

19. Panobianco MS, Pimentel AV, Almeida AM, Oliveira ISB. Mulheres com Diagnóstico Avançado do Câncer do Colo do Útero: Enfrentando a Doença e o Tratamento RBC, 2012[acesso em 2018 jul 8];58(3):517-523. Disponível em: <http://www.inca.gov.br/rbc//n_58/v03/pdf/22_ artigo_mulheres_diagnostico_avan\%C3\%A7ado_cancer_ colo_utero_enfrentando_doenca_tratamento.pdf>.

20. Brasil. Ministério do Desenvolvimento Social e Combate à Fome. Plano nacional de Assistência Social- PNAS/ 2004. Brasília. DF: Ministério da Saúde; 2010.

21. Berlinguer GA. Doença. Centro Brasileiro de Estudos da Saúde. Rio de Janeiro: Cebes; São Paulo: Editora Hucitec; 1988.

22. Silber TJ, Maddaleno M, Munist M, Suarez Ojeda EN. Manual Medicina de la Adolescencia. Washington DC: Organización Panamericana de La Salud; 1992.

Recebido em 12/4/2018

Aprovado em 10/7/2018 